\title{
The relationship between pruritus and clinical variables in patients with psoriasis*
}

\author{
Anil Gulsel Bahali ${ }^{1}$ \\ Ozlem $\mathrm{Su}^{1}$ \\ Didem Dizman ${ }^{2}$ \\ Omer Uysal ${ }^{4}$
}

\author{
Nahide Onsun ${ }^{1}$ \\ Dilek Biyik Ozkaya ${ }^{1}$ \\ Bugce Topukcu ${ }^{3}$
}

DOI: http:/ / dx.doi.org/10.1590/abd1806-4841.20175402

\begin{abstract}
BACKGROUND: Pruritus is the most commonly occurring subjective symptom of dermatological disease. Published data on both prevalence and intensity of pruritus in psoriasis is limited.

ОвјестіVE: In this study we aimed to investigate the prevalence of pruritus and its relation with psoriasis area severity index, body mass index and presence of systemic disease in patients with psoriasis.

Methods: We analyzed data of psoriatic patients diagnosed in our psoriasis outpatient clinic between March 2013 and June 2014 collected retrospectively from PSR-TR registration system.

RESULTS: In total, 880 patients were analyzed. Pruritus was more prominent in female patients. This difference was statistically significant. No significant associations were found between age of patients, clinical type of disease and pruritus. The itching was more common in patients with higher body mass index. Presence of pruritus was correlated significantly with severity of psoriasis. Five hundred and sixty of 880 patients had no systemic disease. The presence of pruritus was not related with presence of systemic disease. Existence of systemic disease with psoriasis has minimal effect on pruritus.

STUDy LimitaTions: We did not evaluate intensity of pruritus.

Conclusions: Pruritus is not mentioned within the classical symptoms of psoriasis. Pruritus in psoriasis is a very unpleasant symptom with great potential to impair patient's quality of life and may exacerbate psoriasis as a Koebner phenomenon.
\end{abstract}

Keywords: Patients; Psoriasis; Pruritus

\section{INTRODUCTION}

Pruritus is the most commonly occurring subjective symptom of dermatological disease and some systemic conditions. It is a very bothersome symptom that may impair the patient's quality of life. ${ }^{1,2}$ Psoriasis is one of the most frequent chronic inflammatory skin diseases, characterized by a complex, multifactorial, and still not fully understood etiopathogenesis. Its worldwide prevalence is approximately $1-3 \% .^{3}$ Although some patients with psoriasis vulgaris complain of varying degrees of pruritus, this has not been regarded as a major psoriasis symptom in many leading textbooks and the literature.-6 Despite a reported global prevalence of pruritus ranging from $64 \%$ to $97 \%$, the clinical characteristics, effective treatment modalities, and pathophysiology of pruritus in psoriasis remain poorly understood..$^{7-9}$ The aim of the present study was to investigate the prevalence of pruritus and its relation with the psoria- sis area severity index (PASI), body mass index (BMI), and presence of systemic disease in a large group of psoriasis patients.

\section{METHODS}

Patients with psoriasis diagnosed in outpatient clinic between March 2013 and June 2014 were enrolled in the study. This cross-sectional study consisted of 880 patients. Clinical data of 880 patients (396 men, 484 women) were collected retrospectively from the psoriasis registry system. Patients with missing records were excluded from the study. Patients of any age diagnosed with psoriasis of any clinical type and severity of disease were enrolled in the study. PASI scores, BMI, age, sex, clinical type of psoriasis, and relation to pruritus were investigated. Patients having pruritus due to associated pruritic dermatoses (atopic dermatitis, scabies, urticaria, etc.) were also excluded. Psoriatic

\section{Received on 18.11.2015.}

Approved by the Advisory Board and accepted for publication on 12.06.2016.

* Study conducted at the Department of Dermatology, Medical Faculty, Bezmialem Vakif University - Istanbul, Turquia.

Financial support: None.

Conflict of interest: None.

\footnotetext{
Department of Dermatology, Medical Faculty, Bezmialem Vakif University - Istanbul, Turquia.

Department of Dermatology, Ardahan State Hospital - Ardahan, Turkey.

Department of Dermatology, Medistate Hospital - Istanbul, Turquia.
}

Department of Biostatistics, Medical Faculty, Bezmialem Vakif University - Istanbul, Turquia. 
patients with systemic disease were not excluded in order to evaluate the effect of systemic disease on pruritus. We assessed only the presence of pruritus in patients but did not rate the severity of pruritus. The severity of psoriasis was calculated using PASI.

\section{Statistical Analysis}

Descriptives are presented as means, standard deviations, and percentages. The Chi-square test was used to compare categorical variables between groups. An independent sample $t$ test was used to compare quantitative variables presented as means and standard deviations between groups. Mann-Whitney $U$ test was used for comparing the score type variables. The median and interquartile ranges were descriptive measures chosen for the quantitative variables of asymmetric distribution. Poisson regression analyses were conducted to assess the determinants of pruritus. Statistical analyses were conducted using IBM SPSS version 19.0. A $p$ value of 0.05 was considered significant.

\section{RESULTS}

Demographic features of patients included in the trial are shown in table 1 . Of the total 880 patients, 553 had pruritus $(62.8 \%)$; 324 of those 553 patients with pruritus were women. The number of female patients with pruritus was higher than male patients. A significant relation existed between female gender and pruritus. The majority of patients included in our trial had plaque type psoriasis (681 patients, $77.4 \%$ ). No significant relation was observed between clinical type of psoriasis and pruritus $(\mathrm{p}=0.052)$. Mean age of patients with pruritus was $43.6 \pm 16.7$ years and mean age of patients without pruritus was $44.2 \pm 16.5$ years; this difference was not statistically significant. BMI and pruritus were also correlated: mean BMI was $28.2 \pm 7.0$ in patients with pruritus and $27.2 \pm 6.3$ in non-pruritic patients. A significant relation also occurred between high PASI

TABLE 1: Characteristics of patients included in the trial

\begin{tabular}{ccccc} 
& $\begin{array}{c}\text { Pruritus } \\
(\mathrm{N}=553)\end{array}$ & $\begin{array}{c}\text { No pruritus } \\
(\mathrm{N}=327)\end{array}$ & $\begin{array}{c}\text { Total } \\
(\mathrm{N}=880)\end{array}$ & $p$ \\
\hline Mean age & $43.6 \pm 16.7$ & $44.2 \pm 16.5$ & $43.8 \pm 16.6$ & 0.649 \\
\hline Gender & & & & \\
\hline Female & $324(59)$ & $160(49)$ & 484 & 0.005 \\
\hline Male & $229(41)$ & $167(51)$ & 396 & \\
BMI & $($ mean $)$ & $28.2 \pm 7.0$ & $27.2 \pm 6.3$ & 0.025 \\
PASI & (median) & $\begin{array}{c}2.70 \\
(\mathrm{IQR}=4.87)\end{array}$ & $\begin{array}{c}0.80 \\
(\mathrm{IQR}=1.70)\end{array}$ & 0.001 \\
\hline
\end{tabular}

scores and presence of pruritus. Median PASI score was 2.70 (IQR= 4.87 ) in psoriasis patients with pruritus and 0.80 (IQR=1.70) in patients without pruritus. Results of Poisson regression analyses are shown in table 2. Of the 880 patients, 32 (3.6\%) reported depression and using antidepressants drugs. Of the patients who had depression, only 20 had pruritus and 12 had no pruritus. There was no significant correlation between pruritus and depression $(p=0.968)$. In total, 560 of the 880 patients had no systemic disease. No significant relation was found between associated systemic disease and presence of pruritus in patients with psoriasis. The results and characteristics of patients without systemic disease with psoriasis are shown in table 3. In this patient population, the results of Poisson regression analyses are shown in table 4 .

\section{DISCUSSION}

Local inflammatory mechanisms may induce pruritus in several dermatoses. Although psoriasis is defined as a non-pruritic skin disease, recent studies reported that pruritus is a very common and bothersome symptom for psoriatic patients. Published data on both prevalence and clinical manifestation of pruritus in psoriasis is limited and the results are contradictory. Pruritus is observed in about $70-90 \%$ of patients with psoriasis and the disease is significantly correlated with impairment of quality of life and associated with depressive symptoms. In a recent study, patients with psoriasis declared that pruritus was their most important symptom. ${ }^{8-12}$

We found a relatively high prevalence of pruritus in psoriatic patients (62.8\% of patients), but our rate was lower than that reported in previous studies. Our results and the number of included patients were similar to those of Sampogna's study. Prevalence of pruritus reported in previous studies is shown in table 5. ${ }^{9-11,13-22}$ The differences in the results may be related to regional features and clinical characteristics of patients.

\begin{tabular}{ccccc} 
TABLE 3: Characteristics of patients without associated systemic \\
disease \\
\hline & $\begin{array}{c}\text { Pruritus } \\
(\mathrm{N}=344)\end{array}$ & $\begin{array}{c}\text { No pruritus } \\
(\mathrm{N}=216)\end{array}$ & $\begin{array}{c}\text { Total } \\
(\mathrm{N}=560)\end{array}$ & $p$ \\
\hline Mean age & $37.2 \pm 14.2$ & $38.4 \pm 14.6$ & $37.6 \pm 14.3$ & 0.308 \\
\hline Gender & & & \\
\hline Female & $185(54)$ & $95(44)$ & 280 & 0.024 \\
\hline Male & $159(46)$ & $121(56)$ & 280 & \\
\hline BMI & $($ mean $)$ & $26.5 \pm 6.1$ & $25.5 \pm 5.7$ & 0.046 \\
\hline PASI & (median) & $\begin{array}{c}2.70 \\
(\mathrm{IQR}=4.67)\end{array}$ & $\begin{array}{c}0.80 \\
(\mathrm{IQR}=1.70)\end{array}$ & 0.001 \\
\hline
\end{tabular}

\begin{tabular}{|c|c|c|c|c|c|c|c|}
\hline & \multirow[t]{2}{*}{ B } & \multirow[t]{2}{*}{ S.E. } & \multirow[t]{2}{*}{ Wald } & \multirow[t]{2}{*}{ PR } & \multirow[t]{2}{*}{$p$} & \multicolumn{2}{|c|}{ \%95 C.I. for OR } \\
\hline & & & & & & Lower & Upper \\
\hline Age & -0.00298 & 0.00325 & 0.84 & 0.99703 & 0.3591 & 0.99070 & 1.00339 \\
\hline Sex & 0.17823 & 0.08880 & 4.03 & 1.19511 & $0.0447^{*}$ & 1.00421 & 1.42229 \\
\hline BMI & 0.00655 & 0.00717 & 0.83 & 1.00657 & 0.3613 & 0.99252 & 1.02082 \\
\hline Systemic disease & 0.05977 & 0.10375 & 0.33 & 1.06159 & 0.5645 & 0.86626 & 1.30097 \\
\hline PASI & 0.03971 & 0.00792 & 25.11 & 1.04051 & $<0,001^{*}$ & 1.02447 & 1.05680 \\
\hline
\end{tabular}




\begin{tabular}{|c|c|c|c|c|c|c|c|}
\hline & \multirow[t]{2}{*}{ B } & \multirow[t]{2}{*}{ S.E. } & \multirow[t]{2}{*}{ Wald } & \multirow[t]{2}{*}{ PR } & \multirow[t]{2}{*}{$p$} & \multicolumn{2}{|c|}{ \%95 C.I. for OR } \\
\hline & & & & & & Lower & Upper \\
\hline Age & 0.00168 & 0.00286 & 0.34 & 1.00168 & 0.5576 & 0.99608 & 1.00731 \\
\hline Sex & -0.09463 & 0.07293 & 1.68 & 0.90971 & 0.1944 & 0.78854 & 1.04950 \\
\hline BMI & -0.00503 & 0.00710 & 0.50 & 0.99499 & 0.4791 & 0.98123 & 1.00893 \\
\hline PASI & -0.02603 & 0.00914 & 8.11 & 0.97430 & $0.0044^{*}$ & 0.95700 & 1.30097 \\
\hline
\end{tabular}

TABLE 5: Prevalence of pruritus in psoriasis in different studies

\begin{tabular}{|ccc|}
\hline Studies & Patients $\mathbf{( N )}$ & Pruritus (\%) \\
\hline Stinco et al. 2014 & 230 & 80 \\
Janowski et al. 2014 & 174 & 98.3 \\
Singh et al. 2013 & 614 & 79 \\
Reich et al. 2010 & 102 & 89.2 \\
Yosipovitch et al. 2000 & 101 & 84 \\
Amatya et al. 2008 & 80 & 80 \\
Szepietowski 2002 & 100 & 80 \\
Roblin et al. & 157 & 97.5 \\
Newbold et al. 1997 & 200 & 92 \\
Gupta et al. 1998 & 82 & 67 \\
Bilaç et al. 2009 & 87 & 96.6 \\
Samponga et al. 2004 & 936 & 63.8 \\
Prignano et al. 2009 & 90 & 83 \\
Bahalı et al. 2014 & 880 & 62.8
\end{tabular}

Pruritus was more prominent in the female population in our study $(324 / 553,59 \%)$. Statistical analysis revealed that pruritus was statistically higher in women with psoriasis than in men. This relation was supported by Poisson regression analyses. Singh et al. found a similarly more common prevalence and severity of pruritus in women, and this gender difference was statistically significant. In addition, they found no difference between adult and pediatric patients; i.e., the age of the patients did not make any difference in terms of pruritus. ${ }^{14}$ In our country, Bilac et al. reported that symptoms were more pronounced in women. ${ }^{20}$ Reich, Prignano, and Szepietowski reported that pruritus was not related to the age or gender of the patients. ${ }^{11,15,22}$ Some studies also evaluated the relation between marital status, alcohol consumption, smoking, education level, place of residence, type of psoriasis, disease duration, family history of psoriasis, and pruritus, but detected no differences. ${ }^{9,15}$ Our results also suggested that the presence of pruritus was not related to clinical type of psoriasis, in agreement with a few studies. ${ }^{11}$

In our study, the presence of pruritus was correlated with BMI and PASI scores. Results of studies showing a relation between PASI and pruritus are conflicting. Some authors observed no correlation with PASI scores and pruritus, but we found a positive relation with high PASI scores and pruritus. This result was supported by Poisson regression analysis. This analysis showed that one point increase in PASI score also increases the prevalence of pruritus at $4 \%$. Singh et al. found some differences in the prevalence and intensity of pruritus between mild psoriasis and severe psoriasis, but these differences were not statistically significant. Prignano et al., as well as other authors, found no relation between the presence and

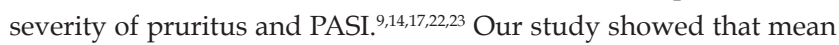
PASI scores were higher in patients with pruritus compared with patients without pruritus, in agreement with some studies, but we did not compare severity scores for pruritus with PASI scores. ${ }^{10,11}$ This is one of the weakness of our study, as the trauma caused by itching may lead to development of new psoriatic lesions due to the Koebner phenomenon and this effect could increase the severity of the disease.

A few studies have shown that BMI was higher in patients with psoriasis than in the normal population. ${ }^{24-26}$ Results of Prignano's study indicated that prevalence and intensity of pruritus were correlated with BMI. ${ }^{22}$ In our study, we also observed a correlation between BMI and pruritus but this correlation was not verified by Poisson regression analysis. Nevertheless, we think that it might there be a relation between BMI and pruritus. The number of obese and overweight patients with pruritus was higher than the number of normal weight patients. Yosipovitch et al. found that ambient heat was an important daily factor for increasing pruritus. Cormia suggested that heat can increase the itch sensation by its effect on dermal nerve endings. ${ }^{9,27}$ Sweating and increased body temperature in obese patients could induce pruritus.

Pruritus is widely recognized as a symptom of various systemic diseases such as uremia. ${ }^{28}$ In general, patients with systemic diseases were excluded from the most studies that evaluated pruritus associated with psoriasis. In the present study, we included patients with systemic disease in order to investigate the relation between prevalence of pruritus and presence of systemic disease in psoriasis patients. Poisson regression analysis showed that one point increase in PASI reduces $3 \%$ the prevalence of pruritus in these patients population. We concluded that systemic disease had minimal effect on pruritus in patients with psoriasis. Our aim in including these patients in our study was to determine the impact, if any, of systemic disease on pruritus in psoriasis.

The pruritus associated with psoriasis is resistant to conventional pruritus treatments. Some authors have suggested that this pruritus has different mediators apart from histamine and have proposed discrete mechanisms for pathogenesis of this pruritus. ${ }^{8,29-31}$ Treatment-resistant pruritus is an additional factor that may aggravate psoriasis due to the additional stress and the Koebner phenomenon; this result is actually not surprising.

Psoriasis has many comorbidities including depression and anxiety. In the literature, various studies have reported that the prevalence of depression in patients with psoriasis may range from $28 \%$ to $67 \%$. It is well known that psychiatric diseases such as depression 
have been associated with pruritus. Some studies have investigated this relation between the severity of pruritus and depression in patients with psoriasis. Remröd et al. found that patients with psoriasis and severe pruritus had high associated depressive scores. ${ }^{31-33}$ In our study we identified only $32(3.6 \%)$ patients who reported depression and used antidepressant drugs. Of the patients who presented depression, only 20 had pruritus. This rate for depression was much lower than in the previous studies in the literature. We believe that these values do not reflect the actual prevalence of depression in these patient groups with psoriasis. Due to the sociocultural characteristics of our country, patients tend to hide their diagnoses of psychiatric disorders such as depression. As a result, we did not find a significant correlation between depression and pruritus because of these lower results.

\section{REFERENCES}

1. Bernhard JD. Itch and pruritus: what are they, and how should itches be classified? Dermatol Ther. 2005;18:288-91.

2. Yosipovitch G.Assesment of itch: more to be learned and improvements to be made. J Invest Dermatol. 2003;121:xiv-xv.

3. Reich A, Szepietowski JC. Vasoactive peptides in the pathogenesis of psoriasis. G Ital Dermatol Venereol. 2008;143:289-98.

4. Roenigk HH, Epstein E, Maibach HI.Skin manifestations of psoriasis and eczematous psoriasis:maturation. In: Roenigk HH, Maiback HI, editors. Psoriasis 3rd ed. New York: Marcel Dekker; 1998. p.3-12

5. Christophers E, Mrowietz U. Psoriasis. In: Freedberg IM, Eisen AZ, Wolff K, Austen KF, Goldsmith LA, Katz S.editors. Fitzpatrick's Dermatology in General Medicine 5th ed.New York:McGraw-Hill; 1999. p.495-521

6. Stern R,Wu J.Psoriasis. In: Arndt KA, LeBoid PE, Robinson JK,Wintroub BU, editors.Cutaneous Medicine and Surgery Philadepphia:WB Saunders; 1996. p.295-321

7. Reich A, Szepietowski JC. Clinical Aspects of Itch: Psoriasis. In: Carstens E, Akiyama T, editors. Itch: Mechanisms and Treatment. Boca Raton (FL): CRC Press; 2014;1-139.

8. Reich A, Szepietowski JC. Mediators of Pruritus in Psoriasis. Mediators Inflamm. 2007;2007:64727

9. Yosipovitch G, Goon A, Wee J, Chan YH, Goh CL.. The prevalence and clinical characteristics of pruritus among patients with extensive psoriasis. Br J Dermatol. 2000;143:969-73.

10. Stinco G, Trevisan G, Piccirillo F, Pezzetta S, Errichetti E, di Meo N, et al. Pruritus in chronic plaque psoriasis: a questionnaire-based study of 230 Italian patients. Acta Dermatovenerol Croat. 2014;22:122-8.

11. Szepietowski JC, Reich A, Wi Acta Dermatovenerol Croat. 2002;10:221-6.

12. Reich A, Hrehorów E, Szepietowski JC. Negative influence of itching on psoriatic patients' well-being. Acta Derm Venereol. 2010;90:257-63.

13. Janowski K, Steuden S, Bogaczewicz J.Clinical and psychological characteristics of patients with psoriasis reporting various frequencies of pruritus. Int $\mathrm{J}$ Dermatol. 2014;53:820-9.

14. Singh KS.Prevalence of pruritus in psoriatic skin lesions and its relations to different variables. Journal of Pakistan Association of Dermatologists. 2013;23:384-7.

15. Reich A, Hrehorów E, Szepietowski JC. Pruritus is an Important Factor Negatively Influencing the Well-being of Psoriatic Patients. Acta Derm Venereol. 2010;90:257-63.

16. Amatya B, Wennersten G, Nordlind K. Patients' perspective of pruritus in chronic plaque psoriasis: a questionnaire-based study. J Eur Acad Dermatol Venereol. 2008;22:822-6.

17. Roblin D, Wickramasinghe R, Yosipovitch G. Pruritus severity in patients with psoriasis is not correlated with psoriasis disease severity. J Am Acad Dermatol. 2014;70:390-1.

18. Newbold PCH.Pruritus in psoriasis. In: Farber EM, Cox AJ, editors. Psoriasis:Proceedings of the Second International Symposium. New York:Yorke Medical Books; 1977. p.334-6

19. Gupta MA, Gupta AK, Kirkby S, Weiner HK, Mace TM, Schork NJ, et al.Pruritus in psoriasis.A prospective study of some psychiatric and dermatologic correlates. Arch Dermatol. 1988;124:1052-7.

\section{CONCLUSION}

In summary, pruritus is not mentioned as a classical symptom of psoriasis, but it is a very unpleasant symptom with great potential to impair a patient's quality of life. If pruritus is controlled in psoriatic patients, their PASI scores could decrease, and needless changes of treatments or increased drug doses might be prevented. However, prospective studies are needed to obtain a better understanding of the pathogenesis of pruritus and its relation with the clinical findings of psoriasis. Dermatologists should be aware of the presence of pruritus in their patients when deciding upon therapeutic approaches for psoriasis. $\square$

20. Bilac C, Ermertcan AT, Bilac DB, Deveci A, Horasan GD. The relationship between symptoms and patient characteristics among psoriasis patients. Indian J Dermatol Venereol Leprol. 2009;75:551.

21. Sampogna F, Gisondi P, Melchi CF, Amerio P, Girolomoni G, Abeni D; et al. Prevalence of symptoms experienced by patients with different clinical types of psoriasis. Br J Dermatol. 2004;151:594-9.

22. Prignano F, Ricceri F, Pescitelli L, Lotti T. Itch in psoriasis: epidemiology, clinical aspects and treatment options. Clin Cosmet Investig Dermatol. 2009;2:9-13.

23. Nakamura M, Toyoda M, Morohashi M. Pruritogenic mediators in psoriasis vulgaris:comparative evaluation of itch-associated cutaneous factors. $\mathrm{Br} \mathrm{J}$ Dermatol. 2003;149:718-30.

24. Herron MD, Hinckley M, Hoffman MS, Papenfuss J, Hansen CB, Callis KP, et al.Impact of obezity and smoking on psoriasis presentation and management. Arch Dermatol. 2005;141:1527-34.

25. Yosipovitch G, DeVore A, Dawn A. Obezity and the skin:skin physiology and skin manifestatins of obezity. J Am Acad Dermatol. 2007;56:901-16.

26. Sterry W, Strober BE, Menter A; International Psoriasis Council. Obezity in psoriasis:the metabolic,clinical and therapeutic implications.Report of an interdisciplinary conference and review. Br J Dermatol. 2007;157:649-55.

27. Cormia FE. Experimental histamine pruritus:influences of physical and psychological factors on threshold activity. J Invest Dermatol. 1952;19:21-34.

28. Kosmadakis GC, Zerefos N..Uremic pruritus. Int J Artif Organs. 2006;29:938-43.

29. Dawn A, Yosipovitch G. Treating itch in psoriasis. Dermatol Nurs. 2006;18:227-33.

30. Wisnicka B,Szepietowski JC, Reich A, Orda A. Histamine, substance P and calcytonin gene-relaed peptide plasma concentration and pruritus in patients suffering from psoriasis. Dermatol Psychosom. 2004;5:73-8.

31. Szepietowski JC, Reich A. Pruritus in psoriasis: An update. Eur J Pain. 201620:41-6

32. Lakshmy S, Balasundaram S, Sarkar S, Audhya M, Subramaniam E. A Crosssectional Study of Prevalence and Implications of Depression and Anxiety in Psoriasis. Indian J Psychol Med. 2015;37:434-40.

33. Remröd C, Sjöström K, Svensson Å. Pruritus in psoriasis: a study of personality traits, depression and anxiety. Acta Derm Venereol. 2015;95:439-43.

How to cite this article: Bahali AG, Onsun N, Su O, Ozkaya DB, Dizman D, Topukcu B, Uysal O. The relationship between pruritus and clinical variables in patients with psoriasis. An Bras Dermatol. 2017;92(4):470-3. 